\title{
Selected properties of the potato snacks expanded in the microwave radiation
}

\author{
Marcin Mitrus ${ }^{1, *}$, Martyna Golian ${ }^{1}$, Maciej Combrzyński ${ }^{1}$, and Arkadiusz Matysiak ${ }^{2}$ \\ ${ }^{1}$ University of Life Sciences in Lublin, Department of Food Process Engineering, Doswiadczalna str. 44, 20-285 Lublin, Poland \\ ${ }^{2}$ POL-FOODS Sp. z o.o., Kolejowa str. 1d, 19-335 Prostki, Poland
}

\begin{abstract}
The results of measurements of the selected properties of the extruded potato pellets and snacks expanded in the microwave field are presented in the paper. The potato pellets with the addition of the baking soda were prepared with a single screw extruder TS-45. The snacks were obtained by pellets expansion in a conventional microwave oven. The expansion index and the hardness of the pellets and the snacks, as well as, the texture properties of the snacks were evaluated during this study. The results showed that baking soda addition reduced the potato pellet expansion during their extrusion. This was an effect of a smaller thickness of the obtained pellets. The addition of baking soda had positive influence on potato snacks expansion in microwave radiation. The higher content of the soda additive resulted in lower hardness of pellets during cutting tests. The opposite effect was observed during texture measurements of the snacks. The addition of baking soda increased hardness of the expanded snacks. Soda addition lowers crispness and fragilityof the potato snacks expanded in the microwave radiation.
\end{abstract}

\section{Introduction}

Generally speaking, extrusion-cooking of vegetable raw materials deals with extrusion of ground material at hydro-thermal conditions. With the help of shear energy, exerted by the rotating screw, and additional heating of the barrel, the food material is heated to its melting point or plasticizing point $[1,2]$. In this changed rheological status the food is conveyed under high pressure through a die or a series of dies and the product expands to its final shape.

Expansion involves the nucleation and growth of vapour bubbles during intensive heat. Superheated steam pressure inside each bubble is the driven force for bubble growth. Finally, as the vapour quickly evaporates, the extrudate expands. To improve the expansion degree, special additives can be used during extrusion process [3]. Zazueta-Moralez et al. [4] suggested that addition of $0.2 \%$ of the calcium hydroxide improves quality characteristic of the extrudates from corn flour. Martinez-Bustos et al. [5] reported that addition of the $0.15 \%$ of calcium hydroxide increase radial expansion index but, in the same time, decrease whole expansion index. Lai et al. [6] reported that addition of the sodium bicarbonate increased expansion index, in contrary to Parsons et al. [7] who reported decrease of expansion index caused by sodium bicarbonate.

Extrusion-cooking leads to production of the products with the physical and chemical properties much different in comparison to the raw materials used. The extruders have a capability to perform cooking tasks under high pressure. This aspect may be explained for vulnerable food and feed as an advantageous process since small time span exposures to high temperatures will restrict unwanted denaturation effects on e.g. proteins, amino acids, vitamins, starches and enzymes. Physical technological aspects like heat transfer, mass transfer, and residence time distribution have a strong impact on the food and feed properties during extrusioncooking and can drastically influence the final product quality. Currently, extrusion-cooking as a method is used for the manufacture of many food and feed products as well as for modification a variety of other materials like thermoplastic starch or cellulose [8-21].

Extrusion-cooked products, often called snacks, belong to so called impulse food. They are growing in popularity because, during the day, consumers prefer a few small portion snacks instead of two or three big meals. In addition these snacks are preferred due to a good taste. Pellets are the extrusion-cooked semiproducts for snacks production. They can be kept in dry storage for 12 months due to theirs compact structure and low humidity $[1,2,17]$.

Pellets belong to the third generation of snacks. They are produced mainly from cereal and potato starch. In addition to the basic raw materials, other materials (milk, meat and pulses) may be used. However, the total amount of the starch in the recipe should be at least $60 \%$ $[1,22]$.

The snacks are produced from pellets by hot oil frying or toasting. This process leads to final starch gelatinisation and pellets expansion. 
In comparison to the traditional hot oil frying, the relatively new process of pellets expansion by microwave heating was developed. This process has gained the popularity due to elimination of the fat from the recipe.

The aim of the work was to investigate the effect of addition of the baking soda on potato pellets and snacks expansion and texture properties.

\section{Materials and methods}

\subsection{Materials}

Potato starch, potato flakes and potato grits were purchased from Zakłady Przemysłu Ziemniaczanego "LUBLIN" Sp. z o.o. (Lublin, Poland). Baking soda (sodium bicarbonate) and salt were purchased from the local market.

Blends of potato starch, potato flakes, potato grits and salt $(50 / 25 / 24 / 1 \%$ of d.m.) with addition of $0-2 \%$ of baking soda were used for manufacturing of the pellets by extrusion-cooking technique. Just before extrusion water was added to the blends to obtain blends with $32 \%$ of moisture content.

\subsection{Pellets and snacks preparation}

Manufacturing of potato pellets was carried out using a single screw extrusion-cooker TS-45 (Polish design) with $\mathrm{L} / \mathrm{D}=18$. A die with one flat opening $(30.0 \times 0.3 \mathrm{~mm})$ was used. The temperature zones in the extruder were $85,95,65$ and $95^{\circ} \mathrm{C}$. The extruder screw speed $60 \mathrm{rpm}$ was used.

The extrudate was manufactured in the form of flat ribbons that were cut into square pellets. The pellets were dried to a moisture content $9 \pm 0.2 \%$ in a shelf drier $\left(40^{\circ} \mathrm{C}\right)$ and then stored in sealed polyethylene bags before microwave heating.

The pellets were expanded by using a microwave oven $(2450 \mathrm{MHz}, 1000 \mathrm{~W}$, Philips M914, the Netherlands). Between tests, the oven was open and the chamber was cooled to room temperature. The pellets (10 pieces) were placed on the rotary table of the oven and heated for $45 \mathrm{sec}$ using at the highest power. The heating conditions were based on preliminary experiments and were constant for all samples.

\subsection{Expansion index}

The expansion index of the pellets was calculated as the pellet cross section area (wide $\mathrm{x}$ thickness) to the die opening area ratio.

Expansion index of the snacks was calculated as the thickness of the expanded snack to the thickness of the pellet ratio. The thickness for each sample (pellet and snack) was measured in, marked earlier, 5 points. The average from measurements of 10 samples (50 points total) was taken as a result.

\subsection{Texture properties}

A Zwick testing machine (BDO-FB0.5TH, Zwick Roell, Germany) was used to measure texture properties for both the potato pellets and expanded snacks.

Hardness of the pellets and snacks was measured during cutting test with Warner-Bratzler test device. The hardness was evaluated as maximum cutting force during straight knife cutting test. The knife speed was $500 \mathrm{~mm} / \mathrm{min}$. The measurements were made in 20 repetitions.

The texture properties (hardness, crispness and fragility) of the microwave expanded snacks were evaluated during double compression test with Ottawa cell. The samples, consisted of one layer of 3 snacks each, were tested at a compression speed of 100 $\mathrm{mm} / \mathrm{min}$. The samples were compressed to a $1 \mathrm{~mm}$ thickness. The measurements were made in 10 repetitions.

\section{Results and discussion}

\subsection{Expansion index}

Compared to microwave puffed grains there are very few studies about microwave heated starch pellets and their properties. The expansion index of the pellets without soda addition was relatively high $(5.72 \pm 0.15)$. The results showed that addition of baking soda reduced the potato pellet expansion during their extrusion (Fig. 1). This was an effect of a smaller thickness of the obtained pellets. The greater amount of soda caused greater reduction of the pellets expansion index. Thermal decomposition of sodium bicarbonate becomes quite rapid above $120^{\circ} \mathrm{C}$ [23]. During extrusion in lower temperature a baking soda could bind some water from the bland and act as an emulsifier. As a result, lower expansion index was observed.

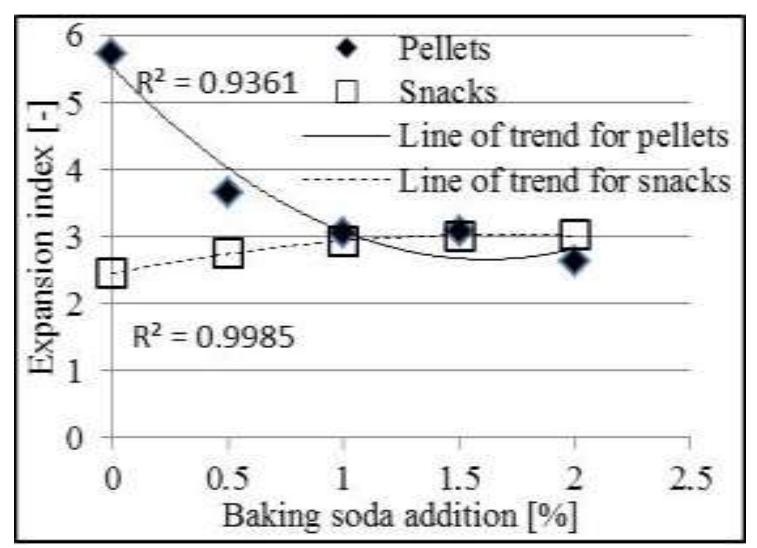

Fig. 1. Changes of expansion index of potato pellets and snacks with addition of baking soda.

Microwave heating is a relatively inexpensive technique that offers advantages such as convenience and fast heating. The formation of the final structure of the snacks is based on the transition of the glassy matrix to the rubbery state during microwave heating. Upon heating, moisture generates the superheated steam 
necessary for expansion. As the result, starchy matrix undergoes a phase transition to rubbery state and starts to deform under steam high pressure and expansion take place. The final structure sets when moisture evaporates from matrix and without microwave heating matrix cools down $[3,24,25]$.

During the research it was found that the addition of baking soda had positive influence on potato snacks expansion in microwave radiation. Expansion index value increased from $2.45 \pm 0.25$ to $3.02 \pm 0.33$ with increase of additive level from 0 to $2 \%$. During microwave heating there is a rapid rise in pellet temperature with can lead to thermal decomposition of baking soda and formation of the $\mathrm{CO}_{2}$ take place. Combined action of $\mathrm{CO}_{2}$ and steam induces greater snacks expansion during microwave heating. Similar soda effect was observed by other researchers [25]. Additionally, the other products of the thermal decomposition of the baking soda can react with the starch. These reactions can leads to reduction of the glass transition temperature of the starch which can facilitate the expansion of the snacks. Similar interaction between salt and starch was observed by Norton et al. [26] during hot air expansion of the potato pellets.

\subsection{Texture properties}

The observations for pellets and snacks hardness during cutting tests are presented on Figure 2. Pellets hardness varied from $36.1 \pm 0.56$ to $14.4 \pm 0.45 \mathrm{~N}$ and decreased with increase of the baking soda addition. These results can be correlated with the change of the pellets thickness due to their expansion index reduction during the extrusion process.

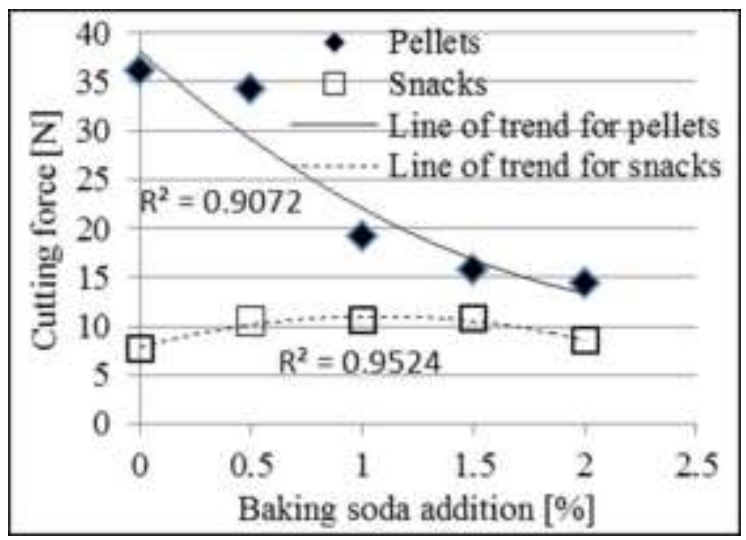

Fig. 2. Changes of hardness of potato pellets and snacks with addition of baking soda.

The opposite effect was observed for snacks expanded during microwave heating (Fig. 2). Maximum cutting force during snacks measurements varied from $7.72 \pm 0.1$ (for $0 \%$ of additive) to $10.7 \pm 0.21$ (for $1.5 \%$ of additive). The addition of baking soda, up to $1.5 \%$, increased hardness of the expanded snacks. Further increase in the amount of the additive, up to $2 \%$,resulted in a slight decrease of the snacks hardness. These results can also be related with snacks thickness changes due to their expansion dependent on sodium bicarbonate content in the blend.

Similar trends in hardness changes were observed for snacks during double compression tests in Ottawa cell. The hardness increased with increase sodium bicarbonate level up to $1.5 \%$. Further increase in addition content resulted in slight potato snacks hardness decrease.

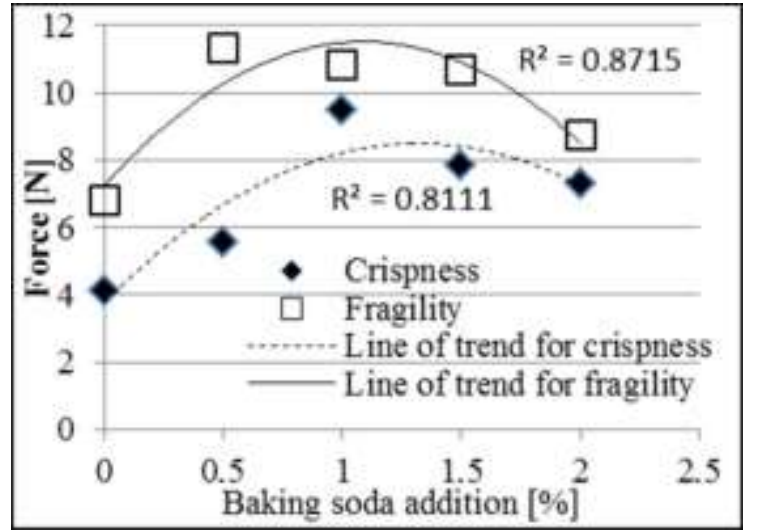

Fig. 3. Crispness and fragility of the microwave expanded snacks with addition of baking soda.

The measurements performed during compression tests revealed the soda bicarbonate influence on snacks textural properties (Fig. 3). Value of force recorded during first crack of the sample was interpreted as crispness. Greater force indicated lower crispness. The baking soda addition had negative effect on snacks crispness. The snacks without soda addition were characterised by the highest crispness. Snacks with sodium bicarbonate had lower crispness. The lowest crispness was observed for snacks with $1 \%$ of soda content. Further baking soda content increase caused crispness decrease.

The value of force needed for sample breaking was interpreted as fragility. Higher force indicated lower fragility. The baking soda addition had positive effect on fragility of microwave heated snacks in comparison to snacks without this additive. This additive increased snacks resistance for breaking. Increase in soda additive caused decrease in snacks fragility. In the other hand, this influence of soda on may be received as unfavourable by consumers.

\section{Conclusions}

1. The investigations showed that, generally, soda bicarbonate had positive influence on potato pellets as well as microwave expanded snacks properties. The addition of baking soda reduced the potato pellet expansion during their extrusion and had positive influence on potato snacks expansion in microwave field.

2. Soda bicarbonate addition decreased potato pellets hardness. In the case of snacks, this additive increased their hardness and fragility but decreased crispness. These changes may be disadvantageous from the consumer point of view. 


\section{References}

1. Leszek Mościcki, Extrusion-Cooking Techniques. Applications, Theory and Sustainability (Wiley$\mathrm{VCH}$, Weinheim, 2011)

2. C. Mercier, P. Linko, J.M. Harper, Extrusion cooking (American Association of Cereal Chemists Inc, St. Paul, 1989)

3. C.I. Moraru, J.L. Kokini. Compr. Rev. Food Sci. Food Saf. 2, 147 (2003)

4. J.J Zazueta-Moralez, F. Martinez-Bustos, N. JacoboValenzuela, C. Ordorica-Falomir, O. Paredes-Lopez, J. Sci. Food Agric. 81, 1379 (2001)

5. F. Martinez-Bustos, Y.K. Chang, A.C. Bannwart, P.A. Rodriguez, P.A. Guedes, E.R. Gaiotti, Cereal Chem. 75, 796 (1998)

6. C.S. Lai, J. Guetzlaff, R.C. Hoseney, Cereal Chem. 66, 69 (1989)

7. M.H. Parsons, F. Hsieh, H.E. Huff, J. Food Process. Preserv. 20, 221 (1996)

8. L. Guz, A. Sopinska, T. Oniszczuk, Aquacult. Nutr. 17, 695 (2011)

9. A. Bouasla, A. Wojtowicz, M. N. Zidoune, LWT Food Sci. Technol. 75, 569 (2017)

10. T. Oniszczuk, R. Pilawka, Przem. Chem. 92, 265 (2013)

11. A. Oniszczuk, A. Wójtowicz, T. Oniszczuk, M. Olech, R. Nowak, K. Wojtunik, M. Klimek, W. Krawczyk, M. Hajnos, Open Chem. 13, 1209 (2015)

12. S. Sharma, N. Singh, B. Singh, Starch/Stärke 67, $721(2015)$

13. K. Mezreb, A. Goullieux, R. Ralainirina, M. Queneudec, Carbohydr. Polym. 64, 1 (2006)

14. D. Gumul, M. Krystyjan, K. Buksa, R. Ziobro, T. Zięba, Starch/Stärke 66, 190 (2014)

15. Y. Ai, K.A. Cichy, J.B. Harte, J.D. Kelly, P.K.W. Ng, Food Chem. 211, 538 (2016)

16. L.C. Oliveira, C.M. Rosell, C.J. Steel, Int. J. Food Science Technol. 50, 1504 (2015)

17. X. Tovar-Jimenez, J. Caro-Corrales, C.A. GomezAldapa, J. Zazueta-Moralez, V. Limon-Valenzuela, J. Castro-Rosas, J. Hernandez-Avila, E. AguilarPalazuelez, Int. J. Food Science Technol. 52, 6607 (2015)

18. Q-B. Ding, P. Ainsworth, A. Plunkett, G. Tucker, H. Marson, J. Food Eng. 73, 142 (2006)

19. M. Wolz, U. Kulozik, J. Food Eng. 209, 12 (2017)

20. A.A.M. Andersson, R. Andersson, A. Jonsäll, J. Andersson, H. Fredriksson, J. Food Sci. 82, 1344 (2017)

21. M. Mitrus, L. Moscicki, Chem. Eng. Res. Des. 92, 778 (2014)

22. A.K. Hardacre, S.M. Clark, S. Riviere, J.A Monro, A.J. Hawkins, J. Texture Stud. 37, 94 (2006)
23. M. Hartman, K. Svoboda, M. Pohořelý, M. Šyc, Ind. Eng. Chem. Res. 52, 10619 (2013)

24. C. Boischot, C.I. Moraru, J.L. Kokini, Cereal Chem. 80, 56 (2003)

25. R.G.M. van der Sman, J.R. Bows, J. Food Eng. 211, 69 (2017)

26. A.D. Norton, R.W. Greenwood, I. Noble, P.W. Cox, J. Food Eng. 105, 119 (2011) 